\title{
Thrombocytopenia Subsequently Develops Systemic Lupus Erythematosus \\ - Can Anti-SS-A Antibody Predict the Next Event?
}

\author{
Masanori ADACHI*, Seiji MITA, Mitsuo OBANA, \\ Yasuo MATSUOKA, Keiichi HARADA and Shoichiro IRIMAJIRI
}

\begin{abstract}
In order to detect diagnostic clues to identify patients with chronic immune thrombocytopenia which is likely to develop systemic lupus erythematosus (SLE), a retrospective study was conducted. Of 39 patients with chronic immune thrombocytopenia, 4 fulfilled the diagnostic criteria being between 4.5 and 14 years after the initial diagnosis of "idiopathic" thrombocytopenic purpura. The remaining 35 patients were found to be idiopathic thrombocytopenic purpura (ITP) after at least a 5-year follow-up. It was noted that in patients with SLE who had thrombocytopenia at presentation, only 4 or 5 findings of diagnostic criteria were observed. Of particular interest, all patients who developed SLE were positive for anti-SS-A antibody, in contrast none of the patients with ITP had this antibody. Furthermore, despite the few clinical manifestations, we noted lupus peritonitis in 1 patient and pulmonary hypertension in another patient. In conclusion, the anti-SS-A antibody is an excellent clue for the early detection of SLE occurring as "idiopathic" thrombocytopenic purpura.
\end{abstract}

Key words: Immune thrombocytopenia, Antinuclear antibody, Lupus peritonitis, Pulmonary hypertension

Early in the course of systemic lupus erythematosus, immune thrombocytopenia may be the sole manifestation. In fact, thrombocytopenic purpura is the earliest clinical manifestation in $3 \%$ to $16 \%$ of patients who subsequently develop systemic lupus erythematosus (1). Furthermore, a positive test for antinuclear antibodies in patients with idiopathic thrombocytopenic purpura often presents diagnostic and therapeutic controversy. Early diagnosis of those with "idiopathic" thrombocytopenic purpura who will ultimately develop systemic lupus erythematosus is important to prevent emergence of the more serious manifestations of systemic lupus erythematosus. To diagnose these patients as early as possible, we investigated the early diagnostic clues through a retrospective study of patients with immune thrombocytopenia.

\section{PATIENTS AND METHODS}

\section{Patients}

From 1965 to 1983 , we treated 39 patients with chronic immune thrombocytopenia who were evaluated by immunological examinations for various antinuclear antibodies. All patients were inor outpatients of Kawasaki Municipal Hospital. An initial clinical diagnosis of "idiopathic" thrombocytopenic purpura was made. Diagnostic criteria for "idiopathic" thrombocytopenic purpura included: 1) increased platelet destruction as manifested by thrombocytopenia or shortened platelet survival i.e., compensated thrombocytolytic states, 2) normal or increased numbers of

From Department of Internal Medicine, Kawasaki Municipal Hospital, Kawasaki (*Now, Research Center of Comprehensive Medicine, School of Medicine, University of the Ryukyus, Okinawa)

Received for publication June 26, 1989; Accepted for publication July 24, 1990

Reprint requests should be addressed to Masanori Adachi, MD, PhD, FJSIM**, Research Center of Comprehensive Medicine, School of Medicine, University of the Ryukyus, 207 Uehara, Nishiharacho, Okinawa 903-01, Japan

**Fellow of the Japanese Society of Internal Medicine 
megakaryocytes in the bone marrow, and 3) the absence of other causes of platelet destruction. The diagnosis of systemic lupus erythematosus was based on the 1982 revised criteria of the American Rheumatism Association.

\section{Methods}

Sera were tested for antinuclear antibodies by an indirect immunofluorescence (FANA) method using Hep-2 cells, a continuous cell line from laryngeal carcinoma. Sera that were positive for FANA were tested for identification with prototype sera specific for precipitating antibodies to Sm, U1-RNP, SS-A and SS-B by double immunodiffusion against human spleen and calf thymus extract. These sera were also tested for antibodies to native DNA by radioimmunoassay (2). Sera were collected from patients with thrombocytopenia before any therapy was started. Blood was drawn at room temperature. Sera were stored at $-70^{\circ} \mathrm{C}$ until analysis.

All patients were followed up at our hospital for at least 5 years. Chi-square analysis with Yates' correction was used for discrete variables.

\section{RESULTS}

\section{Clinical findings of immune thrombocytopenia}

The patients ranged from 15 to 59 years old with a mean of 36 years. There were 30 females and 9 males. Of the 39 patients, $34(87 \%)$ had some manifestations caused by thrombocytopenia including hemorrhagic eruption in $27(69 \%)$, gum bleeding in $10(26 \%)$, epistaxis in $9(23 \%)$, menorrhagia in $7(18 \%)$, sustained bleeding after operation in $3(8 \%)$, hematochezia in $2(5 \%)$ and hematuria in $1(3 \%)$. When the initial diagnosis of "idiopathic" thrombocytopenic purpura was made, only these manifestations due to thrombocytopenia were observed (Table 1).

Thrombocytopenia of less than $20000 / \mathrm{mm}^{3}$ was found in $21(54 \%)$. Of these 21,11 patients had a more severe form of thrombocytopenia with less than $10000 / \mathrm{mm}^{3}$. Anemia was the next most frequent laboratory finding and was observed in 9 $(23 \%)$. Anemias were present only to the extent of blood loss. No Coombs-positive hemolytic anemia was observed in association with thrombocytopenia. An immunological study disclosed that fluorescent antinuclear antibody was positive in $9(23 \%)$. Among extractable nuclear antibodies, anti-nRNP
Table 1. Immune thrombocytopenia: Demographic and clinical findings.

\begin{tabular}{|c|c|c|c|}
\hline \multicolumn{3}{|l|}{ Findings $(n=39)$} & \multirow[t]{2}{*}{ no. $(\%)$} \\
\hline Age, yr., mean & \multicolumn{2}{|l|}{36 (range $15-59$ ) } & \\
\hline Sex, F/M & \multicolumn{2}{|l|}{$30 / 9$} & \\
\hline \multicolumn{2}{|c|}{ Bleeding manifestations } & $34(87)$ & \\
\hline \multicolumn{2}{|c|}{ Hemorrhagic eruption } & & $27(69)$ \\
\hline \multicolumn{2}{|c|}{ Gum bleeding } & & $10(26)$ \\
\hline \multicolumn{2}{|c|}{ Epistaxis } & & $9(23)$ \\
\hline \multicolumn{2}{|c|}{ Menorrhagia } & & $7(18)$ \\
\hline \multicolumn{2}{|c|}{ Bleeding after operation } & & $3(8)$ \\
\hline \multicolumn{2}{|c|}{ Hematochezia } & & $2(5)$ \\
\hline \multicolumn{2}{|c|}{ Hematuria } & & $1(3)$ \\
\hline \multicolumn{2}{|c|}{ Thrombocytopenia, severe } & $21(54)$ & \\
\hline \multicolumn{2}{|c|}{$10000-20000 / \mathrm{mm}^{3}$} & & $10(26)$ \\
\hline \multicolumn{2}{|c|}{ less than $10000 / \mathrm{mm}^{3}$} & & $11(28)$ \\
\hline \multicolumn{2}{|l|}{ Anemia } & $9(23)$ & \\
\hline \multicolumn{2}{|c|}{ Hemoglobin $8-10 \mathrm{~g} / 100 \mathrm{ml}$} & & $4(10)$ \\
\hline \multicolumn{2}{|c|}{ less than $8 \mathrm{~g} / 100 \mathrm{ml}$} & & $3(8)$ \\
\hline \multicolumn{2}{|l|}{ FANA } & $9(23)$ & \\
\hline \multicolumn{2}{|c|}{ Anti-DNA antibody } & $1(3)$ & \\
\hline \multicolumn{2}{|c|}{ Anti-Sm antibody } & $0(0)$ & \\
\hline \multicolumn{2}{|l|}{ BFP } & $1(3)$ & \\
\hline \multicolumn{2}{|c|}{ Anti-RNP antibody } & $1(3)$ & \\
\hline \multicolumn{2}{|c|}{ Anti-SS-A antibody } & $4(10)$ & \\
\hline
\end{tabular}

FANA, fluorescent antinuclear antibody; BFP, biological false positive for serological test for syphilis

antibody was positive in only $1(3 \%)$ and anti-SS-A antibody was noted in $4(10 \%)$ (Table 1$)$.

\section{The titer and pattern of FANA in immune thrombocytopenia}

The results of the test for antinuclear antibodies by indirect immunofluorescence (FANA) in 39 patients with immune thrombocytopenia showed 9 patients had antinuclear antibodies. The titer and pattern of FANA seen in 9 patients is shown in Table 2. A high titer of over 1:256 of FANA was present in 2, a low titer of below that in 7. The most frequent pattern of FANA was the homogeneous type which was present in 4 . The next most frequent pattern was speckled which was found in 3 . A mixed pattern, shaggy and speckled was found in 1, and another mixed pattern, homogeneous and speckled in 1. The patient with the highest antinuclear antibody titer had anti-nRNP antibody.

It was notable that the antibody to SS-A antigen was positive in 4 patients with FANA. These 4 patients fulfilled the 1982 revised criteria of the 
Table 2. Antinuclear antibody in immune thrombocytopenia.

\begin{tabular}{|c|c|c|c|c|c|c|}
\hline \multirow{2}{*}{ Patient } & \multirow{2}{*}{$\begin{array}{l}\text { Age } \\
\text { at } \\
\text { diagnosis }\end{array}$} & \multirow{2}{*}{ Sex } & \multicolumn{2}{|c|}{ FANA } & \multirow{2}{*}{ Precipitation } & \multirow{2}{*}{$\begin{array}{l}\text { Final } \\
\text { diagnosis }\end{array}$} \\
\hline & & & Titer & Pattern & & \\
\hline 1 & 33 & $\mathrm{~F}$ & $1: 256$ & Homogeneous & SS-A & SLE \\
\hline 2 & 21 & $\mathrm{~F}$ & $1: 10$ & Speckled & SS-A & SLE \\
\hline 3 & 19 & $\mathrm{~F}$ & $1: 5120$ & $\begin{array}{l}\text { Homogeneous \& } \\
\text { Speckled }\end{array}$ & $\begin{array}{l}\text { SS-A, } \\
\text { RNP }\end{array}$ & SLE \\
\hline 4 & 43 & $\mathrm{~F}$ & $1: 20$ & $\begin{array}{l}\text { Shaggy \& } \\
\text { Speckled }\end{array}$ & SS-A & SLE \\
\hline 5 & 29 & $\mathrm{~F}$ & $1: 20$ & Homogeneous & - & ITP \\
\hline 6 & 26 & $\mathrm{~F}$ & $1: 10$ & Homogeneous & - & ITP \\
\hline 7 & 29 & $\mathrm{~F}$ & $1: 20$ & Speckled & - & ITP \\
\hline 8 & 52 & $\mathrm{~F}$ & $1: 80$ & Speckled & - & ITP \\
\hline 9 & 34 & $\mathrm{~F}$ & $1: 20$ & Homogeneous & - & ITP \\
\hline
\end{tabular}

American Rheumatism Association used for the diagnosis of systemic lupus erythematosus from 4.5 to 14 years after the initial diagnosis of "idiopathic" thrombocytopenic purpura. The remaining 5 FANA-positive patients were found to be idiopathic thrombocytopenic purpura after at least a 5-year follow-up.

Characteristics of patients with immune thrombocytopenia which develop SLE

The bleeding manifestations in patients with immune thrombocytopenia who develop SLE tended to be more severe than in those with idiopathic thrombocytopenic purpura. Profound thrombocytopenia of less than $10000 / \mathrm{mm}^{3}$ was found in $50 \%$ of the patients with SLE. On the other hand, it was noted in only $26 \%$ of patients with ITP. But the difference between the two groups was not statistically significant.

Among the patients with systemic lupus erythematosus who showed "idiopathic" thrombocytopenic purpura at initial presentation, only 4 or 5 findings of diagnostic criteria were observed. Furthermore, despite the few clinical manifestations, lupus peritonitis was observed in 1 patient, and pulmonary hypertension in 1 (Table 3 ), which are rare in systemic lupus erythematosus. FANA was positive in all patients with systemic lupus erythematosus, and in 5 out of 35 patients with idiopathic thrombocytopenic purpura. The patients with systemic lupus erythematosus did not always have a high titer FANA as shown in Table 2. None of the four patients had anti-Sm antibody. Of particular interest, all patients who developed systemic lupus were positive for anti-SS-A antibody, in contrast none of the idiopathic thrombocytopenic purpura patients had this antibody.

\section{Clinical characteristics of FANA-positive ITP}

Five patients whom we treated for more than 10 years were proved to be FANA positive idiopathic thrombocytopenic purpura (one patient had a follow-up period of only 5 years). In addition to bleeding manifestations, arthralgia which was seen in 1 patient was the only clinical manifestation noticed during the observation period. Leukopenia was the only abnormal laboratory finding listed in the diagnostic criteria other than positive FANA and thrombocytopenia (Table 4).

The study design and main results are given in Fig. 1.

\section{DISCUSSION}

In the evaluation of patients with thrombocytopenia, bone marrow aspiration to evaluate the megakaryocyte count, and a careful review of the patient's medication are mandatory. The patients, in this study, had no drug-related platelet destruction. An increased megakaryocyte counts in the bone marrow was confirmed in all patients. In addition, at the time of presentation with thrombocytopenia, no clinical manifestations suggestive of systemic 
Table 3. SLE patients profile.

\begin{tabular}{|c|c|c|c|c|}
\hline No. & Age/Sex & $\begin{array}{l}\text { Time required } \\
\text { to confirm } \\
\text { diagnosis }\end{array}$ & $\begin{array}{l}\text { No. of the } \\
\text { revised } \\
\text { criteria of ARA }\end{array}$ & Clinical findings \\
\hline 1 & $33 / F$ & $4.5 \mathrm{yr}$ & 5 & $\begin{array}{l}\text { Malar rash } \\
\text { Arthritis } \\
\text { LE cells* } \\
\text { FANA* } \\
\text { Anti-SS-A antibody* }\end{array}$ \\
\hline 2 & $21 / \mathrm{F}$ & $5.2 \mathrm{yr}$ & 5 & $\begin{array}{l}\text { Malar rash } \\
\text { Proteinuria } \\
\text { Lupus peritonitis } \\
\text { FANA* } \\
\text { Anti-SS-A antibody* } \\
\text { Anti-DNA antibody }\end{array}$ \\
\hline & & & & $\begin{array}{l}\text { Malar rash } \\
\text { Proteinuria } \\
\text { Pulmonary hypertension }\end{array}$ \\
\hline 3 & $19 / F$ & $5 \mathrm{yr}$ & 5 & $\begin{array}{l}\text { BFP* } \\
\text { FANA* } \\
\text { Anti-SS-A antibody* }\end{array}$ \\
\hline 4 & $43 / F$ & $14 \mathrm{yr}$ & 4 & $\begin{array}{l}\text { Malar rash } \\
\text { Arthritis } \\
\text { FANA* } \\
\text { Anti-SS-A antibody* }\end{array}$ \\
\hline
\end{tabular}

*Present at initial diagnosis of ITP

Table 4. Clinical characteristics of FANA-positive ITP.

\begin{tabular}{lccll}
\hline No. & $\begin{array}{c}\text { Age } \\
/ \\
\text { Sex }\end{array}$ & $\begin{array}{l}\text { Observation } \\
\text { period, } \\
\text { yr }\end{array}$ & $\begin{array}{l}\text { Clinical manifestations } \\
\text { other than bleeding } \\
\text { tendency }\end{array}$ & $\begin{array}{l}\text { Laboratory findings } \\
\text { other than FANA } \\
\text { and thrombocytopenia }\end{array}$ \\
\hline 1 & $29 / \mathrm{F}$ & 12 & None & None \\
2 & $26 / \mathrm{F}$ & 12 & None & Leukopenia \\
3 & $29 / \mathrm{F}$ & 10 & None & None \\
4 & $52 / \mathrm{F}$ & 15 & None & None \\
5 & $34 / \mathrm{F}$ & 5 & Arthralgia & None \\
\hline
\end{tabular}

lupus erythematosus were observed.

The prevalence of thrombocytopenia, as reported in a study of a large series of patients with systemic lupus erythematosus ranges from $14 \%$ to $26 \%$ (3). Shortened platelet survival is responsible for the low platelet count in systemic lupus erythematosus and the megakaryocytes in the bone marrow are either normal or increased in number. Furthermore, thrombocytopenic purpura is the earliest clinical manifestation in $3 \%$ to $16 \%$ of patients with systemic lupus erythematosus (3). This makes it important to seek evidence of this disease in all patients with immune thrombocytopenia. Breckenridge and associates suggested that idiopathic thrombocyto- 


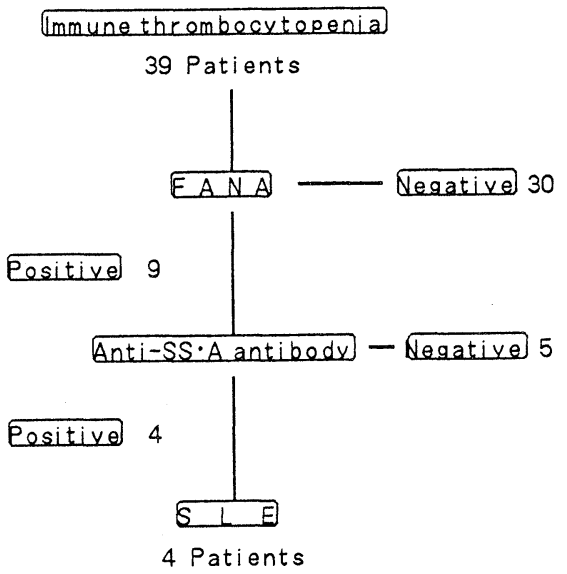

Fig. 1. Diagrammatic schema of the flow chart study.

penic purpura and systemic lupus erythematosus can often be distinguished by histological findings of the spleen (4). These criteria are not practical. In addition, Hayes and coworkers reported that no distinguishable pathologic features in the spleen were found in lupus patients after analysis of the splenic pathology of 73 patients with immune thrombocytopenia including 8 patients with systemic lupus erythematosus (5).

Kelton and Gibbons proposed the measurement of antinuclear antibody to rule out systemic lupus erythematosus among patients with immune thrombocytopenia (6). However, the presence of autoantibodies to certain defined nuclear antigens is commonly associated with specific rheumatic diseases as well as some immunohematologic diseases including idiopathic thrombocytopenic purpura (7). As shown in this study, the occurrence of immune thrombocytopenia and a positive fluorescent antinuclear antibody test is not unusual. In this retrospective study, 5 out of 35 patients with idiopathic thrombocytopenic purpura had a positive test for antinuclear antibodies. It can not be a precise predictor of the patients who will develop systemic lupus erythematosus. It is possible, however, that evaluation of the sera from patients with chronic immune thrombocytopenia and a positive antinuclear antibody assay, using a panel of autoantibodies to nuclear antigens, may show a predictable pattern in patients who later develop systemic lupus. It is of significance that all 4 patients who presented as immune thrombocytopenia and later developed systemic lupus erythematosus had antiSS-A antibody. In contrast, none of the immune thrombocytopenic patients who did not develop systemic lupus had this antibody.

Similar to our results, Morley and associates reported that two patients with anti-SS-A presented isolated idiopathic thrombocytopenic purpura before the development of systemic lupus erythematosus (8). They suggested that anti-SS-A may be a useful marker for the subgroup of patients who present with immune thrombocytopenia and progress to systemic lupus erythematosus. Furthermore, Anderson and associates noted 4 patients with an initial diagnosis of idiopathic thrombocytopenic purpura who developed systemic lupus erythematosus from 1 to 3 years later (7). They emphasized that three of the four of these patients were positive to SS-A. Antibody to an antigen SS-A, which is extractable from a variety of tissues, is found in systemic lupus erythematosus and Sjögren's syndrome (9). Antibody to SS-A antigen has been associated with an increased frequency of photosensitive rash (9). Morley and associates have shown an association between anti-SS-A antibody and the presence of thrombocytopenia; of 32 patients with anti-SS-A antibody, thrombocytopenia occurred in $12(38 \%)$ as compared with 5 out of $32(16 \%)$ patients with systemic lupus erythematosus who lacked the antibody (6). It also frequently occurs in "ANA-negative" systemic lupus erythematosus (10). Alger and associates reported a subgroup of patients with systemic lupus erythematosus characterized by thrombocytopenia, hemolytic anemia, and a more benign prognosis (11). Anti-SS-A antibody may be a marker of this group.

It must be emphasized that the 4 patients in the present study who later developed systemic lupus had only 4 or 5 clinical findings even after fulfilling the diagnostic criteria. The clinical manifestations in these patients were only malar rash and arthritis. Since the diagnosis of idiopathic thrombocytopenic purpura is made by exclusion of other diseases, the differential diagnosis is difficult. Therefore, any clinical marker to predict patients who will ultimately develop systemic lupus would be of considerable value for clinical use. We propose that an assay to determine the anti-SS-A antibody should 
be included in the routine work-up in the evaluation of patients with immune thrombocytopenia. Further, despite the few clinical manifestations, lupus peritonitis was observed in 1 patient and pulmonary hypertension in 1 patient. These have been rare in systemic lupus erythematosus. In conclusion, the antibody to SS-A antibody is an excellent clue for the early detection of patients with immune thrombocytopenia who will subsequently develop systemic lupus erythematosus.

\section{REFERENCES}

1) Karpatkin S. Autoimmune thrombocytopenic purpura. Blood 56: 329, 1980.

2) Nakamura RM, Molden DP, Tan EM, Peebles CL. Autoantibodies to nuclear antigens (ANA). in: Advances in Laboratory Tests and Significance in Systemic Rheumatic Diseases. American Society of Clinical Pathology, Chicago, 1984.

3) Budman DR, Steinberg AD. Hematologic aspects of systemic lupus erythematosus. Current concepts. Ann Intern Med 86: 220, 1977.

4) Breckenridge RT, Moore RD, Ratnoff OD. A study of thrombocytopenia. Blood 30: 39, 1967.

5) Hayes MM, Jacobs P, Wood L, Dent DM. Splenic pathology in immune thrombocytopenia. J Clin Pathol 38: 985,1985 .

6) Kelton JG, Gibbons S. Autoimmune platelet destruction: Idiopathic thrombocytopenic purpura. Semin Thromb Hemost 8: 83, 1982.

7) Anderson MJ, Peebles CL, McMillan R, Curd JG. Fluorescent antinuclear antibodies and anti-SS-A/Ro in patients with immune thrombocytopenia subsequently developing systemic lupus erythematosus. Ann Intern Med 103: 548, 1985.

8) Morley KD, Bernstein RM, Bunn CC, et al. Thrombocytopenia and anti-Ro. Lancet 2: 940, 1981.

9) Alspaugh MA, Tan EM. Antibody to cellular antigens in Sjögren's syndrome. J Clin Invest 55: 1067, 1975.

10) Maddison PJ, Mogavero H, Provost TT, Reichlin M. The clinical significance of autoantibodies to a soluble cytoplasmic antigen in systemic lupus erythematosus and other connective tissue disease. J Rheumatol 6: 189, 1979.

11) Alger M, Alarcon-Segovia D, Rivero SJ. Hemolytic anemia and thrombocytopenic purpura: Two related subsets of systemic lupus erythematosus. J Rheumatol 4: $351,1977$. 